\title{
Characterization of a newly identified ETV6- NTRK3 fusion transcript in acute myeloid leukemia
}

\author{
Johanna M Kralik', Wolfgang Kranewitter ${ }^{1}$, Hans Boesmueller ${ }^{2}$, Renate Marschon ${ }^{1}$, Gertraud Tschurtschenthaler ${ }^{3,4}$, \\ Holger Rumpold ${ }^{4}$, Kurt Wiesinger ${ }^{5}$, Martin Erdel ${ }^{1}$, Andreas L Petzer ${ }^{4}$, Gerald Webersinke ${ }^{1 *}$
}

\begin{abstract}
Background: Characterization of novel fusion genes in acute leukemia is important for gaining information about leukemia genesis. We describe the characterization of a new ETV6 fusion gene in acute myeloid leukemia (AML) FAB MO as a result of an uncommon translocation involving chromosomes 12 and 15.

Methods: The ETV6 locus at 12p13 was shown to be translocated and to constitute the $5^{\prime}$ end of the fusion product by ETV6 break apart fluorescence in situ hybridisation (FISH). To identify a fusion partner 3' rapid amplification of cDNA-ends with polymerase chain reaction (RACE PCR) was performed followed by cloning and sequencing.

Results: The NTRK3 gene on chromosome 15 was found to constitute the $3^{\prime}$ end of the fusion gene and the underlying ETV6-NTRK3 rearrangement was verified by reverse transcriptase PCR. No RNA of the reciprocal NTRK3ETV6 fusion gene could be detected.

Conclusion: We have characterized a novel ETV6-NTRK3 fusion transcript which has not been previously described in AML FAB MO by FISH and RACE PCR. ETV6-NTRK3 rearrangements have been described in secretory breast carcinoma and congenital fibrosarcoma.
\end{abstract}

\section{Background}

Chromosomal translocations resulting in fusion genes with transforming activity are fundamental in leukemia genesis. The ETV6 gene (ETS variant gene 6) on the short arm of chromosome 12 encodes a transcriptional repressor of the ETS transcription factor family which is fundamental in adult hematopoiesis and plays a versatile role in hematological malignancies [1]. ETS family members are essential for a variety of cellular processes including proliferation, differentiation, migration and tissue remodeling, angiogenesis, apoptosis, as well as hematopoiesis and cell transformation [2,3]. ETV6 is a 452 amino acid protein encoded by 8 exons containing the characteristic ETS domain at its carboxy terminus $[4,5]$. The ETS domain harbors DNA binding properties

\footnotetext{
* Correspondence: gerald.webersinke@bhs.at

'Laboratory of Molecular Biology and Tumorcytogenetics, Department of Internal Medicine I, Krankenhaus der Barmherzigen Schwestern, Seilerstaette 4, 4010 Linz, Austria

Full list of author information is available at the end of the article
}

but also mediates protein-protein interactions [1]. ETV6 contains a helix-loop-helix (HLH) domain at its amino terminus which mediates homotypic oligomerization of ETV6 molecules and also heterotypic interactions with other proteins [1,2]. ETV6 is located on band $12 \mathrm{p} 13$ which is genetically unstable and thus susceptible to chromosomal rearrangements [6]. In recent years ETV6 was shown to be involved in a variety of translocations associated with hematological malignancies of both myeloid as well as lymphoid origin $[1,7]$. The diversity of ETV6 rearrangements is striking considering that the breakpoints do not cluster within a particular region of the gene [4].

Fusions between ETV6 and phospho-tyrosinkinases (PTKs) are found in a variety of hematological diseases where the HLH domain is essential for the aberrant function of the fusion product, e.g. chronic myelomonocytic leukemia (CMML), AML, acute lymphoid leukemia (ALL) or myelodysplastic syndrome (MDS) [1]. In other

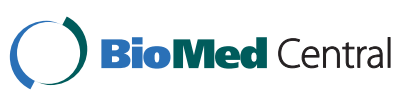

() 2011 Kralik et al; licensee BioMed Central Ltd. This is an Open Access article distributed under the terms of the Creative Commons Attribution License (http://creativecommons.org/licenses/by/2.0), which permits unrestricted use, distribution, and reproduction in any medium, provided the original work is properly cited. 
cases ETV6 has been shown to contribute to the dysregulation of cellular functions by its ETS domain [8].

In the present study we identified the PTK NTRK3 as an ETV6 fusion partner. NTRK3 is a membrane anchored tyrosine kinase and functions as a receptor for the neurotrophin NT-3, regulating development and maintenance of the vertebrate nervous system $[9,10]$. NTRK3 does not only show expression in neural tissues but also in hematopoietic and epithelial cells [10].

The NTRK3 gene is composed of 18 exons; the receptor kinase domain is encoded by exons 13 through 18 . Alternative splicing of NTRK3 leads to different isoforms, one of which is a truncated version of the fulllength protein and does not possess a catalytically active kinase domain but exhibits exons $13 \mathrm{~b}$ and $14 \mathrm{~b}$ as its final two exons [9]. The catalytically active ETV6NTRK3 fusion proteins have been previously detected in non-hematopoietic tumors, e.g. secretory breast carcinoma and congenital fibrosarcoma and in only one single case of hematological malignancy, i.e. an AML [11-13].

\section{Methods}

\section{Patient profile}

The 55-year-old male patient was transferred to our department with a newly diagnosed AML-M0 according to the FAB-classification. The bone marrow showed a 45\% infiltration with AML-blasts, which stained positive for CD33, CD13, CD56 and CD7. Due to that, the patient received a treatment consisting of one induction of cytarabine and idarubicin followed by a second induction of cytarabine and mitoxantrone, a salvage therapy consisting of cytarabine and fludarabine followed by two cycles of gemtuzumab ozogamicine. The leukemic clone was refractory after each treatment cycle with an unchanged blast count in the bone marrow and the patient subsequently died after a short period of best supportive care.

\section{Molecular and cytogenetic diagnostics}

The patient was tested negative for mutations of the NPM1 and FLT3 genes and AML1-ETO- and CBFbMYH11 rearrangements.

Conventional karyotyping using GTG banding of unstimulated bone marrow cultures showed a pathological cell line exhibiting monosomy 7 and a translocation $t$ (10;12)(q24;p13). An ETV6 rearrangement was assumed and could be demonstrated by Dual Color Break Apart FISH (LSI ${ }^{\circledR}$ ETV6 probe; Abbott Molecular) (Figure 1A). Whole chromosome paints (WCPs) (XCP Human Chromosomen Paints; Metasystems) revealed additional material of chromosome 12 on a second chromosome due to a cryptic translocation; chromosome 15 could be identified as a partner. (Figure 1B)

\section{RACE PCR method}

3' nested RACE PCR was performed with the GeneRacerTM Kit (Invitrogen) according to the manufacturer protocol. Primers ETV6A/nested, ETV6B/nested and ETV6C/nested were used (ETV6 GenBank Accession number NM_001987, Version NM_001987.4, see Additional file 1 Table S1 for sequence information) with Platinum ${ }^{\circledR}$ Taq DNA Polymerase High Fidelity (Invitrogen; $5 \mathrm{U} / \mu \mathrm{l})$.

Nested RACE PCR products of interest were excised from the gel and cloned using the TOPO TA Cloning ${ }^{\circledR}$ Kit (Invitrogen) according to the manufacturer's recommendations.

Amplification of cloned RACE PCR products was performed with 0,5 - 1,0 ng plasmid DNA, M13F/R primers and AmpliTaq Gold ${ }^{\mathrm{TM}} \mathrm{DNA}$ Polymerase $(5 \mathrm{U} / \mu \mathrm{l}$; Applied Biosystems). PCR products were purified using the ExoSAP-IT ${ }^{\circledR}$ system (USB) and subsequently sequenced using the BigDye ${ }^{\circledR}$ Terminator v1.1 Cycle Sequencing Kit (Applied Biosystems). Capillary electrophoresis was run in the ABI 3130 Genetic Analyzer (Applied Biosystems).

\section{Reverse transcriptase PCR for expression testing}

cDNA was prepared from total RNA by random hexamer priming (Amersham Biosciences) using M-MLV $\mathrm{RT}$ as indicated by the manufacturer (Promega).

For reverse-transcriptase PCR reactions cDNA was used undiluted with specifically designed primers for ETV6 (ETV6 GenBank Accession number NM_001987, Version NM_001987.4) and NTRK3 exons (GenBank Accession number NM_001012338, version NM_001012338.1 and GenBank Accession number NM_001007156, version NM_001007156.1) as listed in the Additional file 1 Table S1.

\section{Results and Discussion}

Genetic alterations play a key role in the pathogenesis of both solid tumors and hematological malignancies. In recent years the description of these alterations by molecular genetics provided crucial information for risk stratification and therapy, especially for acute leukemias. We describe a novel ETV6 fusion in an AML patient, which was confirmed by FISH and WCP (Figure 1) and could not be detected by routine chromosome banding techniques because it is highly cryptic. Therefore, the translocation is easily overlooked in conventional cytogenetics.

By RACE PCR and sequencing a truncated version of the NTRK3 transcript was found in the forward sequencing reaction containing the polyA tail of the transcript, whereas the reverse reaction identified ETV6 as the 5' part of the transcript. NTRK3 is located on chromosome $15 \mathrm{q} 25$ which is affected in our patient as demonstrated 


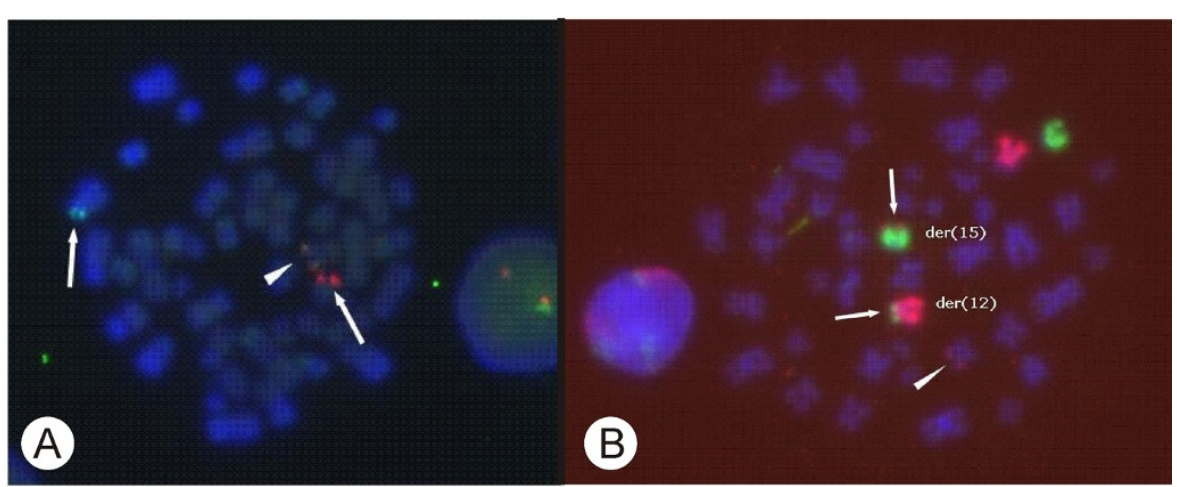

Figure 1 FISH experiments. 1a. ETV6 break apart FISH. Arrows indicate the split signal for one allele, the arrow head marks the fusion signal of the wildtype allele. 1b. WCP of chromosomes 12 (red) and 15 (green). The arrows indicate the reciprocal translocation giving rise to derivate chromosomes der(12) and der(15). The arrow head marks the additional material of chromosome 12 on chromosome 10.

by WCP 12 FISH (Figure 1). Out of 142 sequencing reactions of RACE products, no partner gene on chromosome 10 could be detected. Whole chromosome paints of chromosomes 10 and 15 did not show any translocated signals (data not shown).

Expression of the truncated fusion transcript and possible isoforms was tested in nested RT-PCR experiments (see Figure 2). Results showed that ETV6 and the alternatively spliced, truncated NTRK3 clearly exist as a fusion transcript. Furthermore, the existence of ETV6 being fused to catalytically active NTRK3 was proven. RTPCR amplification products of patient RNA were then

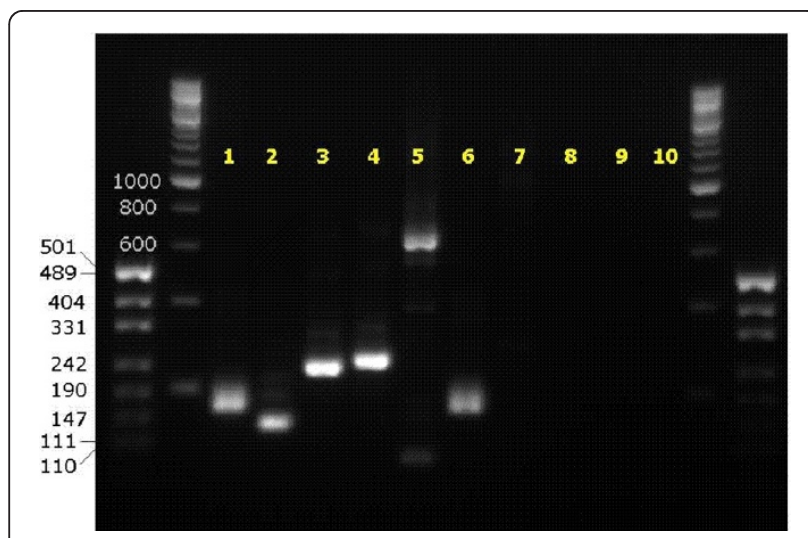

Figure 2 Nested RT-PCR of fusion transcripts. Results indicate that ETV6 builds fusion transcripts with both the truncated and catalytically active NTRK3 (lane numbers explained below). ETV6NTRK3 rearrangement: 1 control PCR of patient with ETV6-NTRK3$\overline{\text { rearrangement }(A B L 1)}$; 2 ETV6 exon5 and NTRK3 exon14; 3 ETV6 exon5 and NTRK3 exon14l; 4 ETV6 exon5 and NTRK3 exon14II; 5 ETV6 exon5 and NTRK3 exon17; all NTRK3 primers are specific for the tyrosine kinase domain. Controls: 6 control PCR of patient without ETV6-NTRK3-rearrangement (ABL1); 7 ETV6 exon5 and NTRK3SequF (patient without ETV6-NTRK3-rearrangement); 10 water control. NTRK3-ETV6 Rearrangement: 8,9 NTRK3 exon12 (2 primers) and ETV6 exon6. sequenced with appropriate primers. Based on these results the proposed entire fusion transcripts contain ETV6 exons 1 through 5 fused to NTRK3 exons $13 \mathrm{~b}$ and 14b or NTRK3 exons 13 through 18 (see Figure 3). Both NTRK3 isoforms are in-frame fusion partners of ETV6. No ETV6-NTRK3 transcripts could be detected in control cDNA from patients without ETV6 rearrangement. The reciprocal translocation product (NTRK3-ETV6) was not detected on the RNA level when patient cDNA was amplified with different primer combinations suggesting its missing expression.

So far, catalytically active ETV6-NTRK3 fusion proteins have been detected in a significant fraction of nonhematopoietic tumors, e.g. secretory breast carcinoma, congenital fibrosarcoma or mesoblastic nephroma $[11,12,14]$. Their transforming ability is based on constitutive activation of the NTRK3 moiety with downstream activation of Ras- MAP kinase and phosphatidyl inositol-3-kinase (PI3K)-AKT pathways [11]. Interestingly, the ETV6-NTRK3 fusion has been reported in only one case of hematological malignancy, i.e. an AML (FAB M2) [13]. Here, we describe the presence of the ETV6NTRK3 fusion in a further AML case which, in contrast belongs to the FAB M0 subgroup. Furthermore, there are two striking differences between the previously detected hematological ETV6-NTRK3 fusion and the one described here. In this context, one needs to point out that ETV6 activity as a transcriptional repressor is achieved by at least two different domains: the HLH domain and the central region located between the HLH and ETS domain encoded by part of exon 4 and the entire exon $5[1,2]$. This central domain was shown to interact with corepressors, whereas the HLH domain represses gene transcription independently from corepressors $[2,15]$. As far as the differences are concerned, the fusion transcript identified in this study exhibits ETV6 exons 1 through 5 in contrast to the previously 


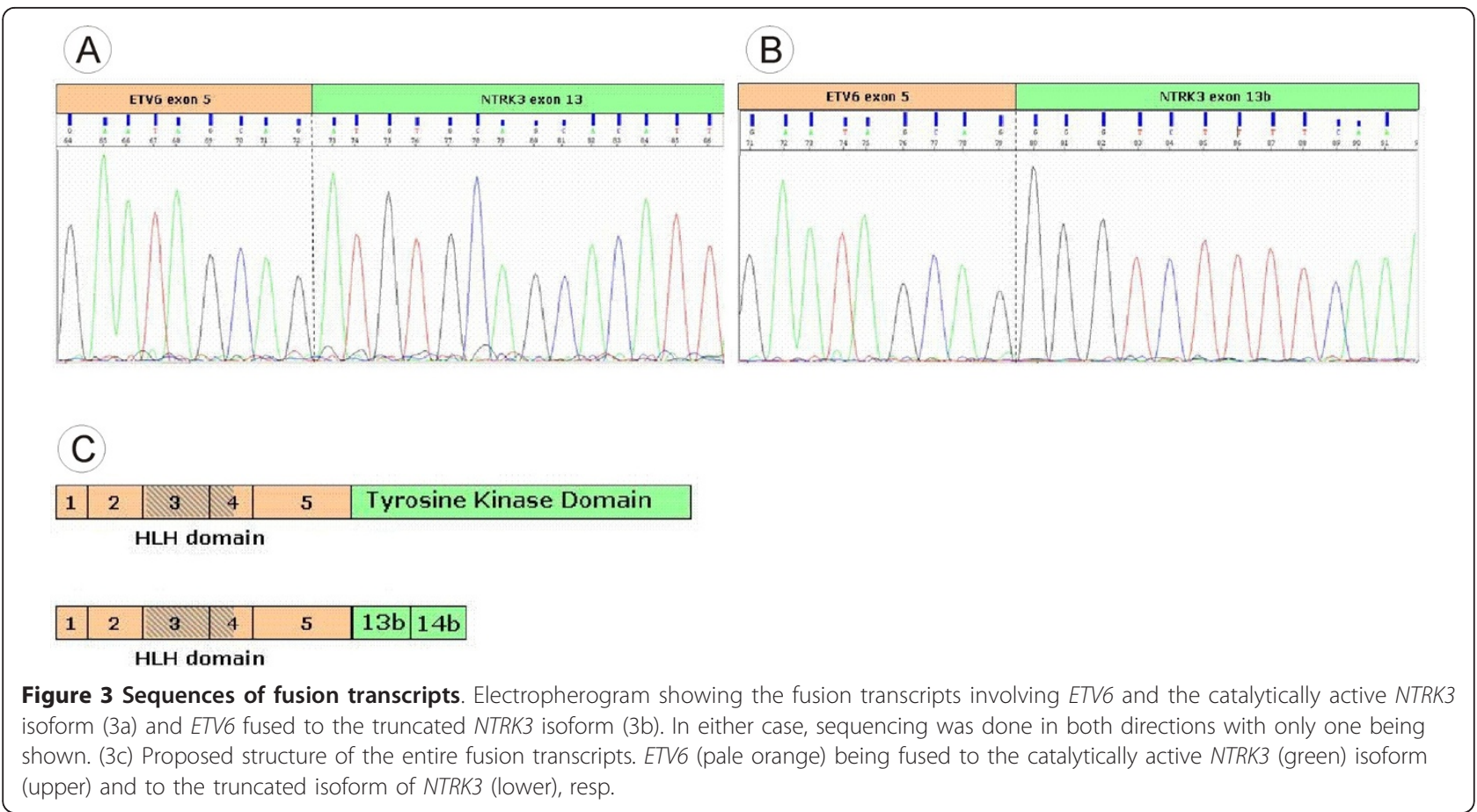

published case which contained only the first four ETV6 exons. Therefore, the entire central domain, made up partly of exon 4 and the entire exon 5, is still present and might enable further protein-protein interactions. The second difference is that ETV6 was shown to be fused to the catalytically active isoform in the earlier report. In our case we demonstrated that alternative splicing of the transcribed ETV6-NTRK3 gene takes place and gives rise to the truncated NTRK3 isoform which is known to induce signaling that results in membrane ruffling and cellular protrusions, structural changes that support cell migration [16].

Unfortunately, insufficient patient material did not allow the investigation of ETV6-NTRK3 expression on the protein level. The oncogenic activity of both variants remains to be revealed. Thereby one must keep in mind that fusion products containing ETV6 have been shown to involve diversely regulated aberrant mechanisms. As far as kinase domain proteins are concerned, ETV6 influences the fusion partner's activity via its HLH (dimerization) domain [8]. Regarding the ETV6-NTRK3 fusion, data prove that the NTRK3 kinase domain by itself does not provoke transformation activity. More precisely, it was demonstrated that NIH3T3 cells cannot be successfully transformed by ETV6-NTRK3 chimeric proteins that still possess a perfectly operating NTRK3 kinase domain but lack a functional ETV6 HLH domain [17]. In other rearrangements, the ETV6 promotor driving the transcription of the fusion gene is thought to confer oncogenic potential [8]. It is possible that the two variants of fusion products identified in this study may function differently in cell transformation.

\section{Conclusion}

We described a novel ETV6 fusion with a gene involved in neuronal development, NTRK3, in AML. The fusion gene has been previously detected in non-hematopoietic tumors, e.g. secretory breast carcinoma and congenital fibrosarcoma. Comparable to other molecular alterations in AML the ETV6-NTRK3 fusion might be of prognostic relevance and should be investigated further in larger patient cohorts.

\section{Additional material}

Additional file 1: Table S1. Primer sequences used in RT-PCR and sequencing analyses.

\section{Author details}

${ }^{1}$ Laboratory of Molecular Biology and Tumorcytogenetics, Department of Internal Medicine I, Krankenhaus der Barmherzigen Schwestern, Seilerstaette 4, 4010 Linz, Austria. ${ }^{2}$ Institute of Pathology, Krankenhaus der Barmherzigen Schwestern, Seilerstaette 4, 4010 Linz, Austria. ${ }^{3}$ Laboratory for Hematology, Department of Internal Medicine I, Krankenhaus der Barmherzigen Schwestern, Seilerstaette 4, 4010 Linz, Austria. ${ }^{4}$ Department of Internal Medicine I; Krankenhaus der Barmherzigen Schwestern, Seilerstaette 4, 4010 Linz, Austria. ${ }^{5}$ Institute of Laboratory Medicine BB\&BS, Krankenhaus der Barmherzigen Schwestern, Seilerstaette 4, 4010 Linz, Austria.

\section{Authors' contributions}

KJM designed and performed research, analyzed data and wrote the paper, KW and MR contributed to molecular studies, TG performed FACS analysis, 
RH and PA contributed clinical data, WK did bone marrow cytology, BHC did bone marrow histology, EM contributed to cytogenetics, WG designed the study, did cytogenetics, analysed the data and cowrote the paper. All authors read and approved the final manuscript.

\section{Competing interests}

The authors declare that they have no competing interests.

Received: 11 January 2011 Accepted: 15 March 2011

Published: 15 March 2011

\section{References}

1. Bohlander SK: ETV6: A versatile player in leukemogenesis. Semin Cancer Biol 2005, 15:162-74.

2. Hart SM, Foroni L: Core binding factor genes and human leukemia. Haematologica 2002, 87:1307-23.

3. Nordentoft I, Jorgensen P: The acetyltransferase $60 \mathrm{kDa}$ trans-acting regulatory protein of HIV type 1-interacting protein (Tip60) interacts with the translocation E26 transforming-specific leukaemia gene (TEL) and functions as a transcriptional co-repressor. Biochem J 2003, 374:165-73.

4. Poirel H, Lacronique V, Le Coniat M, Raffoux E, Daniel MT, Erickson P, Drabkin H, MacLeod RA, Drexler HG, Ghysdael J, Berger R, Bernard OA: Analysis of TEL proteins in human leukemias. Oncogene 1998, 16:2895-903.

5. Baens M, Peeters P, Guo C, Aerssens J, Marynen P: Genomic organization of TEL: the human ETS-variant gene 6. Genome Res 1996, 6:404-13.

6. Manola KN, Georgakakos VN, Margaritis D, Stavropoulou C, Panos C, Kotsianidis I, Pantelias GE, Sambani C: Disruption of the ETV6 gene as a consequence of a rare translocation $(12 ; 12)(p 13 ; q 13)$ in treatmentinduced acute myeloid leukemia after breast cancer. Cancer Genet Cytogenet 2008, 180:37-42.

7. Thandla SP, Ploski JE, Raza-Egilmez SZ, Chhalliyil PP, Block AW, de Jong PJ, Aplan PD: ETV6-AML1 translocation breakpoints cluster near a purine/ pyrimidine repeat region in the ETV6 gene. Blood 1999, 93:293-99.

8. Wlodarska I, La Starza R, Baens M, Dierlamm J, Uyttebroeck A, Selleslag D, Francine A, Mecucci C, Hagemeijer A, Van den Berghe H, Marynen P: Fluorescence in situ hybridization characterization of new translocations involving TEL (ETV6) in a wide spectrum of hematologic malignancies. Blood 1998, 91:1399-1406.

9. Ichaso N, Rodriguez RE, Martin-Zanca D, Gonzalez-Sarmiento R: Genomic characterization of the human trkC gene. Oncogene 1998, 17:1871-75.

10. Hisaoka M, Sheng WQ, Tanaka A, Hashimoto H: Gene expression of TrkC (NTRK3) in human soft tissue tumours. J Pathol 2002, 197:661-7.

11. Tognon C, Knezevich SR, Huntsman D, Roskelley CD, Melnyk N, Mathers JA, Becker L, Carneiro F, MacPherson N, Horsman D, Poremba C, Sorensen PH: Expression of the ETV6-NTRK3 gene fusion as a primary event in human secretory breast carcinoma. Cancer Cell 2002, 2:367-76.

12. Knezevich SR, McFadden DE, Tao W, Lim JF, Sorensen PH: A novel ETV6NTRK3 gene fusion in congenital fibrosarcoma. Nat Genet 1998, 18:184-7.

13. Eguchi M, Eguchi-lshimae M, Tojo A, Morishita K, Suzuki K, Sato Y, Kudoh S, Tanaka K, Setoyama M, Nagamura F, Asano S, Kamada N: Fusion of ETV6 to Neurotrophin-3 receptor TRKC in acute myeloid leukaemia with $\mathrm{t}(12 ; 15)$ (p13;q25). Blood 1999, 93:1355-63.

14. Knezevich SR, Garnett MJ, Pysher TJ, Beckwith JB, Grundy PE, Sorensen PHB: ETV6-NTRK3 gene fusions and trisomy 11 establish a histogenetic link between mesoblastic nephroma and congenital fibrosarcoma. Cancer Res 1998, 58:5046-48.

15. Chakrabarti SR, Nucifora G: The leukemia-associated gene TEL encodes a transcription repressor which associates with SMRT and mSin3A. Biochem Biophys Res Comm 1999, 264:871-7.

16. Esteban PF, Yoon HY, Becker J, Dorsey SG, Caprari P, Palko ME, Coppola V, Saragovi HU, Randazzo PA, Tessarollo L: A kinase-deficient. TrkC receptor isoform activates Arf6-Rac1 signaling through the scaffold protein tamalin. J Cell Biol 2006, 173:291-9.

17. Tognon $C E$, Mackereth $C D$, Somasiri AM, Mclntosh LP, Sorensen HB: Mutations in the SAM domain of the ETV6-NTRK3 chimeric tyrosine kinase block polymerization and transformation activity. Mol Cell Biol 2004, 24:4636-50. doi:10.1186/1746-1596-6-19

Cite this article as: Kralik et al:: Characterization of a newly identified ETV6-NTRK3 fusion transcript in acute myeloid leukemia. Diagnostic Pathology 2011 6:19.

\section{Submit your next manuscript to BioMed Central and take full advantage of:}

- Convenient online submission

- Thorough peer review

- No space constraints or color figure charges

- Immediate publication on acceptance

- Inclusion in PubMed, CAS, Scopus and Google Scholar

- Research which is freely available for redistribution 